\title{
Human Papillomavirus Infection and Its Possible Correlation with p63 Expression in Cervical Cancer in Japan, Mongolia, and Myanmar
}

\author{
Ulziibat Shirendeb ${ }^{1}$, Yoshitaka Hishikawa ${ }^{1}$, Shingo Moriyama ${ }^{2}$, Ne Win ${ }^{3}$, \\ Minn Minn Myint Thu ${ }^{4}$, Khin Swe Mar', Gerlee Khatanbaatar, \\ Hideaki Masuzaki ${ }^{2}$ and Takehiko Koji ${ }^{1}$
}

\begin{abstract}
${ }^{I}$ Department of Histology and Cell Biology, Nagasaki University Graduate School of Biomedical Sciences, Nagasaki, Japan, ${ }^{2}$ Department of Obstetrics and Gynecology, Nagasaki University Graduate School of Biomedical Sciences, Nagasaki, Japan, ${ }^{3}$ Department of Health, National Health Laboratory, Ministry of Health; Department of Public Health Laboratory, University of Public Health; Department of Medical Science, Ministry of Health, Yangon, Union of Myanmar, ${ }^{4}$ Pathology Research Division, Department of Medical Research (Lower Myanmar), Yangon, Union of Myanmar, ${ }^{5}$ Yangon Central Women's Hospital, Yangon, Union of Myanmar and ${ }^{6}$ Oncology Department, Center of Pathology, Ministry of Health, Mongolia
\end{abstract}

Received September 13, 2009; accepted October 10, 2009; published online December 22, 2009

\begin{abstract}
Although human papillomavirus (HPV) 16 is the cause of cervical cancer in most countries including Japan, the involvement of cervical cancer with HPV types in Mongolian and Myanmar populations is largely unknown. We examined the expression of HPV in formalinfixed and paraffin-embedded cervical tissues from 40 Japanese, 32 Mongolian, and 30 Myanmar cervical cancer patients. We performed immunohistochemistry using anti-HPV16 and anti-HPV 1, 6, 11, 16, 18 and 31 cocktail and then correlated it with the expression of Ki-67 and p63. HPV 16 was detected in $72 \%, 65 \%$ and $50 \%$ of Japanese, Mongolian and Myanmar cervical cancer patients, respectively, whereas $5(13 \%)$ of the 40 patients, $8(25 \%)$ of the 32 patients and $7(23 \%)$ of the 30 patients in HPV 16-negative cancers were positive for other HPV types included in the cocktail, respectively. Ki-67 labeling index (LI) as well as p63 LI was significantly higher in HPV 16-positive patients than in HPV 16-negative ones in the Japanese and Mongolian samples. p63 expression was significantly associated with stage III and IV in Japan and Mongolia. These findings suggest that HPV 16 may be associated with cell proliferative activity and tumor progression, possibly depending upon the expression of p63 in the cervical cancer. In addition, immunohistochemical detection for distinguishing the type of HPV may also be useful for cervical cancer in the clinical setting.
\end{abstract}

Key words: HPV, cervical cancer, Japan, Mongolia, Myanmar

\section{Introduction}

Cervical cancer is the second most common cancer in women [23]. Human papillomavirus (HPV) infection has been associated with carcinogenesis and malignant potential of cervical cancer [23, 43]. HPVs are mucosal-trophic viruses infecting basal cells of stratified squamous epithe-

Correspondence to: Professor Takehiko Koji, Department of Histology and Cell Biology, Nagasaki University Graduate School of Biomedical Sciences, 1-12-4 Sakamoto, Nagasaki 852-8523, Japan.

E-mail: tkoji@nagasaki-u.ac.jp lium and represent a common sexually transmitted disease.

There are more than 100 types of HPV, and more than twenty HPV types are widely accepted to be cancerassociated [40]. Moreover, geographical differences in HPV types have been reported to exist in the world [5]. In Mongolia and Myanmar, cervical cancer is the most common type of genital cancer in women. The recent distribution of cervical cancer estimated to be $26.1 \%$ per 100,000 in Japan, $22.5 \%$ per 100,000 in Mongolia, and 23.3\% per 100,000 in Myanmar [26, 39]. In Japan, HPV genotypes 16, $18,31,51,52$ and 58 were associated with squamous cell carcinoma (SCC), whereas HPV 16 and 18 were associated 
with adenocarcinoma (ACC) [29]. Among 110 women who visited a sexually transmitted disease clinic in Ulaanbaatar, Mongolia, 39 women (36\%) were HPV positive, and among HPV-positive patients, genotypes 16, 18, 31, 33, 39, 45, 51 and 52 were found in 17 (44\%) patients by PCR [9]. However, less is known whether HPV genotypes are associated with cervical cancer progression and prognosis in patients from Mongolia and Myanmar compared with Japan.

The recently cloned transcription factor p63 is a promising marker to regulate epithelial proliferation and differentiation of the epidermis [42]. p63 expression has been found in SCC of the oral cavity, lung, head and neck, skin, and esophagus [8, 12, 25, 41]. The loss of p63 expression is associated with tumor progression and decreased survival in endometrial, lung and bladder cancers [19, 34, 37]. In the cervix, p63 is expressed in basal and parabasal cells of ectocervix, maturing transformation zone and cervical intraepithelial neoplasia [16, 27]. Moreover, Wang et al. [38] reported that p63 expression was positive in $94 \%$ of HPV16 and 50\% of HPV18-positive cases in cervical SCC. However, the function of p63 in the carcinogenesis of HPV-positive cervical cancer is not well understood yet.

To detect HPV genotypes, PCR is typically used as a convenient technique. However, the precise spatial localization of various types of HPV within tissues is not well known. To correlate HPV protein expression with aberrant cell states of proliferation and differentiation directly, immunohistochemical analysis is essential.

In this study, we have investigated the expression of HPV genotypes in cervical cancer in samples from Japan, Mongolia, and Myanmar and we addressed, using immunohistochemistry, whether HPV protein expression was associated with the Ki-67 labeling index (LI) and p63 expression in cervical cancer.

\section{Materials and Methods}

\section{Patients and tissue preparation}

Tissue samples included 40 patients (32-73 years) from Japan, 32 from Mongolia (29-53 years) and 30 from Myanmar (32-65 years). In our study, controls included 10 normal cervixes, 15 cervical intraepithelial neoplasia (CIN) biopsy tissues taken from Japanese and Mongolian women, respectively. Control samples from Myanmar were unavailable. The clinicopathological characteristics of the cervical cancer patients are shown in Table 1. The stages of the disease were coded according to International Federation of Gynecology and Obstetrics (FIGO) staging schemes [7]. Patients with stage I and II had undergone a "radical hysterectomy" and thus the entire cervix was available for histological examination, and those with stage III and IV had been treated with radiation and a cervical biopsy obtained prior to therapy was available for assessing the histological type and grade. All specimens were collected in accordance with the approval protocols from the Human Ethics Review Committee of the Nagasaki University School of Medicine, the National Cancer Center of Mongolia and the Cancer registry unit of Yangon General Hospital, Yangon, Myanmar. Informed consent was obtained from all subjects.

The surgical and biopsy specimens were fixed in $10 \%$ buffered formalin and embedded in paraffin. The same paraffin-embedded tissue blocks were used for hematoxylin and eosin staining and immunohistochemistry. Five- $\mu$ mthick sections were mounted on glass slides coated with 3-aminopropyltriethoxysilane (Sigma Chemical Co., St Louis, MO, USA).

\section{Antibodies}

A mouse monoclonal antibody against human HPV 16 (1:50) [10] and a mouse monoclonal antibody against p63 (4A4; TA and $\triangle \mathrm{Np} 63 ; 1: 100)$ were kind gifts from BioGenex (San Ramon, CA, USA). Monoclonal broad spectrum HPV cocktail (1:50) against human HPV types 1, 6, 11, 16, 18 and 31 was purchased from Biocare Medical (Concord, CA, USA) [13]. Mouse monoclonal antibody against Ki-67 (MIB-1; 1:100) was purchased from Dako Cytomation, Kyoto, Japan. Horseradish peroxidase (HRP)-conjugated goat anti-mouse $\operatorname{IgG}(1: 100)$ was purchased from Chemicon International (Temecula, CA, USA). Goat anti-mouse antibody conjugated to Alexa $546(1: 100)$ and FITC labeled sheep anti-mouse antibody (1:400) were purchased from Molecular Probes (Invitrogen, Carlsbad, CA, USA). Normal goat IgG, normal sheep IgG, and normal mouse IgG were purchased from Sigma Chemical Co.

\section{Immunohistochemistry}

Immunohistochemical staining was performed as described previously $[14,20,36]$. Briefly, the sections were dewaxed with toluene, and rehydrated through a graded ethanol series. The sections were autoclaved at $120^{\circ} \mathrm{C}$ for 15 min in $10 \mathrm{mM}$ sodium citrate ( $\mathrm{pH}$ 6.0). After the inhibition of endogenous peroxidase activity with $0.3 \% \mathrm{H}_{2} \mathrm{O}_{2}$ in methanol for $15 \mathrm{~min}$, the sections were pre-incubated with 500 $\mu \mathrm{g} / \mathrm{ml}$ normal goat IgG and $1 \%$ bovine serum albumin in PBS for $1 \mathrm{hr}$. Then, the sections were reacted with the primary antibodies (broad spectrum HPV cocktail, MIB-1, and p63) for $1 \mathrm{hr}$. After washing with $0.075 \%$ Brij 35 in PBS, the sections were incubated with HRP-labeled goat anti-mouse IgG for $1 \mathrm{hr}$. The sites of HRP were visualized with 3,3'-diaminobenzidine tetrahydrochloride (DAB; Dojin Chemical Co., Kumamoto, Japan), $\mathrm{Ni}^{2+}, \mathrm{Co}^{2+}$ and $\mathrm{H}_{2} \mathrm{O}_{2}$. As a negative control, some sections were reacted with normal mouse IgG at the same concentrations instead of the specific antibodies. In the case of HPV 16 staining, the Kyowa staining reagents (Kyowa Medex, Tokyo, Japan) were used. The experimental procedure was completed with an OptiMax Automated Cell Staining System (BioGenex, San Ramon, CA) as described previously $[1,17,21]$.

\section{Double staining}

For simultaneous detection of HPV 16 and p63, we performed double staining, as described previously [31]. SCC samples were double-stained for $\mathrm{Ki}-67$ and p63, and the signals were detected by enzyme-immunohistochemistry 
Table 1. Clinico-pathological characteristics of patients

\begin{tabular}{|c|c|c|c|c|c|c|}
\hline \multirow{2}{*}{$\begin{array}{l}\text { Parameters } \\
\text { Histological type }\end{array}$} & \multicolumn{2}{|c|}{ Japan $(n=40)$} & \multicolumn{2}{|c|}{ Mongolia $(n=32)$} & \multicolumn{2}{|c|}{ Myanmar $(n=30)$} \\
\hline & $\mathrm{SCC}$ & $\mathrm{ACC}$ & $\mathrm{SCC}$ & $\mathrm{ACC}$ & $\mathrm{SCC}$ & $\mathrm{ACC}$ \\
\hline & $\mathrm{n}=28$ & $\mathrm{n}=12$ & $\mathrm{n}=28$ & $\mathrm{n}=4$ & $\mathrm{n}=24$ & $\mathrm{n}=6$ \\
\hline Pregnancy (mean \pm S.D.) & $2.2 \pm 1.2$ & $2.5 \pm 1.4$ & $5.5 \pm 2.3$ & $3.0 \pm 2.6$ & $4.0 \pm 1.8$ & $6.3 \pm 1.9$ \\
\hline Parity (mean \pm S.D.) & $2.3 \pm 1.1$ & $1.9 \pm 1.3$ & $4.4 \pm 2.4$ & $2.3 \pm 2.3$ & $3.4 \pm 1.5$ & $5.1 \pm 1.7$ \\
\hline Age (mean \pm S.D.) & $48.8 \pm 12.5$ & $42.2 \pm 9.0$ & $44.9 \pm 9.2$ & $46.5 \pm 18.8$ & $47.9 \pm 10.6$ & $51.8 \pm 3.6$ \\
\hline \multicolumn{7}{|l|}{ Tumour stage } \\
\hline $\mathrm{I} / \mathrm{II}$ & $7 / 12$ & $5 / 7$ & $4 / 15$ & $2 / 2$ & $6 / 13$ & $1 / 5$ \\
\hline III/IV & $5 / 4$ & $0 / 0$ & $6 / 3$ & $0 / 0$ & $4 / 1$ & $0 / 0$ \\
\hline \multicolumn{7}{|l|}{ Parametrial involvement } \\
\hline $\mathrm{P} 0$ & 10 & 6 & 14 & 4 & 8 & 3 \\
\hline $\mathrm{P} 1$ & 18 & 6 & 14 & 0 & 16 & 3 \\
\hline
\end{tabular}

SCC, squamous cell carcinoma; ACC, adenocarcinoma.

or fluorescence-immunohistochemistry [11, 35]. After antigen retrieval, the sections were stained with anti-HPV 16 (1:50) for $2 \mathrm{hr}$ and HRP sites were visualized with DAB and $\mathrm{H}_{2} \mathrm{O}_{2}$. Ki-67 localization was detected with goat anti-mouse secondary antibody conjugated to Alexa 546 (Molecular Probes). The slides were immersed in $0.1 \mathrm{M}$ glycine- $\mathrm{HCl}$ buffer ( $\mathrm{pH}$ 2.2) three times for $30 \mathrm{~min}$ each. After washing with Milli-Q water once and with PBS three times, the sections were reacted with anti-p63 antibody for $2 \mathrm{hr}$. HRP sites were visualized with 4 Cl-1-naphthol (Kasei Kogyo, Tokyo, Japan) and $\mathrm{H}_{2} \mathrm{O}_{2}$ solution (blue). In the case of immunofluorescent staining, p63 localization was detected with a FITC labeled sheep anti-mouse secondary antibody (Cosmo Bio, Tokyo, Japan). The nuclear staining was performed with 4,6'-diamidino-2-phenylindole dihydrochloride (DAPI; Molecular Probes) and the sections were analyzed with confocal laser scanning microscopy (LSM PASCAL 5, Carl Zeiss, Gottingen, Germany).

\section{Statistical analysis}

For quantitative analysis, more than 2,000 cells were counted in random fields at $\times 400$ magnification, and the p63 LI and Ki-67 LI were expressed as a percentage of positive cells per total number of counted cells. The data were expressed as mean $\pm \mathrm{SD}$. Mean values were compared with unpaired Student's $t$-test, and categorical variables were compared with chi-square test and Fisher's exact probability test. A $p$-value of less than 0.05 was denoted as a statistically significant. Correlation between p63 LI and Ki-67 LI were assessed by linear regression analysis (analysis of variance; ANOVA). All analyses were performed with a statistical software package (StatView, version 5.0; Abacus Concepts, Berkeley, CA).

\section{Results}

\section{Identification of HPV types in cervical cancer}

We investigated the genotypic expression of HPV in samples from different geographic regions, specifically, Japan, Mongolia, and Myanmar. First, we detected the expression of HPV 16 in these three countries. Typical staining of HPV 16 protein is shown in Figure 1. HPV 16 protein was not found in normal cervix, whereas it was detected in CIN and cervical cancer (Fig. 1). The HPV 16 protein was localized in the nuclei and cytoplasm of cancer cells in both SCC and ACC (Fig. 1D, E). When the specimens were reacted with normal mouse $\mathrm{IgG}$, no staining was found (data not shown).

The expression profile of HPV types in samples from Japan, Mongolia, and Myanmar is shown in Figure 2A. HPV 16 was positive in $29(72 \%)$ of the 40 patients in Japan, 21 $(65 \%)$ of the 32 patients in Mongolia, $15(50 \%)$ of the 30 patients in Myanmar, whereas $5(13 \%)$ of the 40 patients, $8(25 \%)$ of the 32 patients and $7(23 \%)$ of the 30 patients in HPV 16-negative cervical cancers were positive for other HPV types included in the cocktail. The overall HPV prevalence was $85 \%$ (34 of 40), 90\% (29 of 32) and 73\% (22 of 30 ) in samples from Japan, Mongolia and Myanmar, respectively. The HPV 16-positive ratio in different histological types of cervical cancer is shown in Figure 2B. In Japan, HPV 16 was found in $26(93 \%)$ of 28 in SCC versus $3(25 \%)$ of 12 in ACC. In Mongolia and Myanmar, HPV 16 was found only in SCC.

\section{Comparison of clinicopathological variables between HPV 16-positive and-negative patients}

HPV 16 was significantly higher in younger women (25-40 years) in Myanmar $(p=0.0012)$, while no significant correlations were observed between HPV 16 infection and age of the patients in Japan and Mongolia (Table 2). HPV 16 was correlated positively with the histological type of cervical cancer in all countries $(p<0.0001 ; p=0.0092 ; p=0.0169)$ and the stage of cervical cancer in Japan $(p=0.0433$; Table 2). However, no significant correlation was observed between HPV 16 positivity and the number of pregnancies, or parities in any of the samples.

\section{Correlation between Ki-67 LI and HPV infection in normal and cancerous cervix}

When cell proliferating activity was assessed by Ki-67 

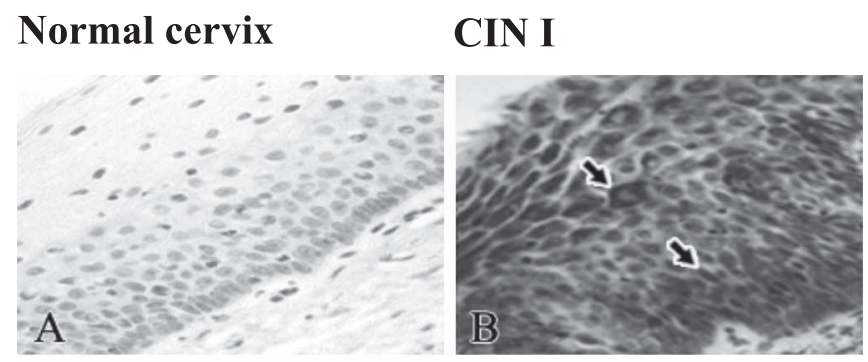

\section{CIN III}

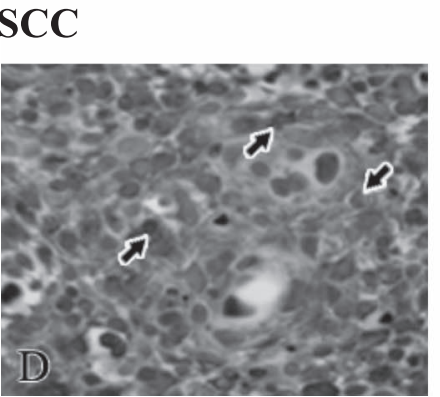

$\mathrm{ACC}$
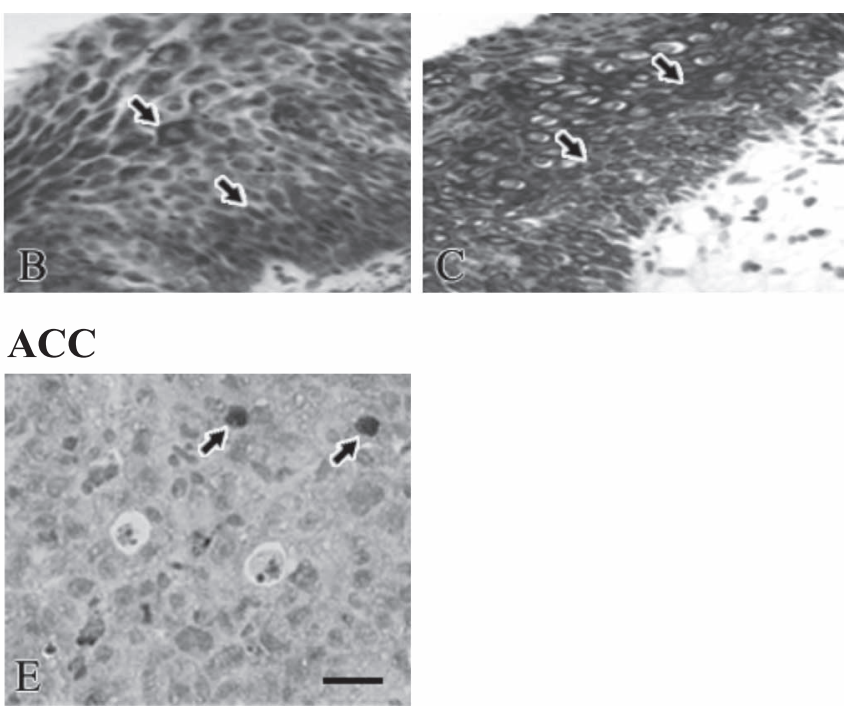

Fig. 1. HPV 16 localization in normal cervix, cervical intraepithelial neoplasia (CIN) I, III, SCC and ACC. (A) HPV 16 was not expressed in normal cervix, whereas (B-E) HPV 16 (arrows) was localized in the nuclei and cytoplasm of squamous epithelial cells in CIN I and CIN III and cancer cells of SCC and ACC.

\section{A HPV-type specific distribution}

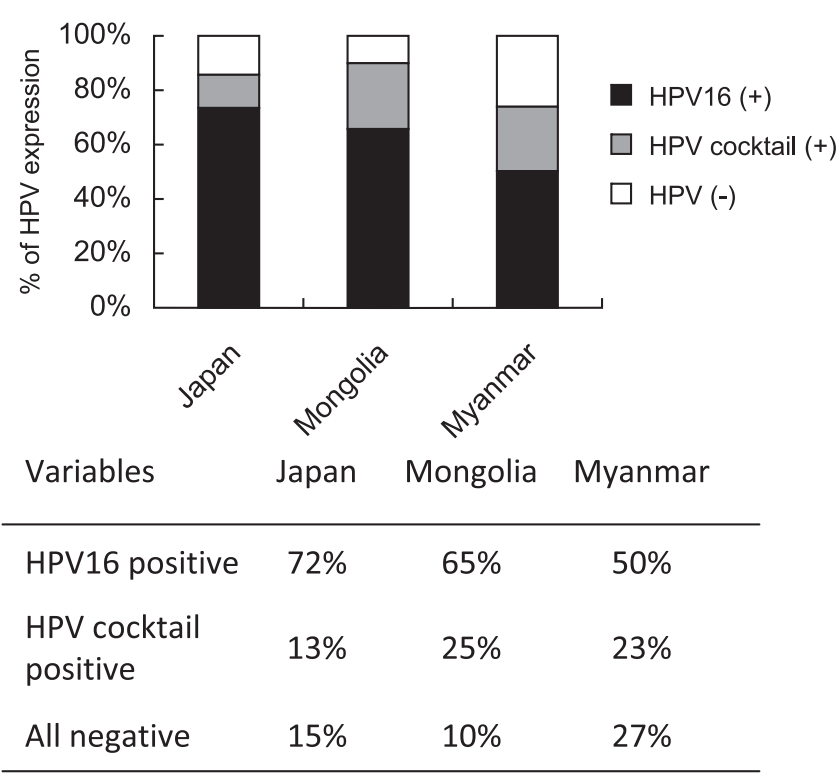

staining, positive findings were observed only in the nuclei of parabasal cells in the normal stratified squamous epithelium of cervix (Fig. 3A). However, in CIN I to III, Ki-67positive cells were spread from parabasal to the superficial layer (Fig. 3B, C). Ki-67 staining was found mostly in the nuclei of cancer cells in SCC and ACC (Fig. 4D-F) and co-localized with HPV proteins (Fig. 4A-C). We also performed quantitative analysis to determine the correlation of Ki-67 LI and HPV 16 positivity. The number of Ki-67 LI

\section{B Distribution of HPV 16}

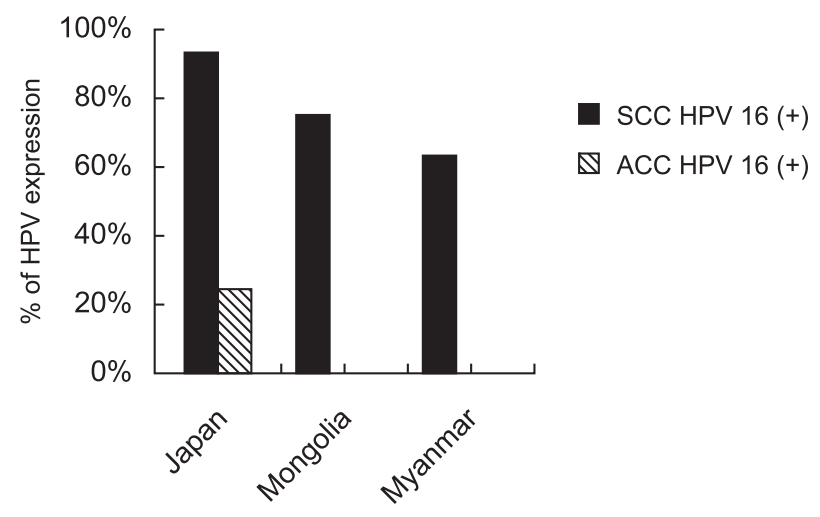

Fig. 2. (A) HPV-type specific distribution among cervical cancer in samples from Japan, Mongolia, and Myanmar. Black bar; HPV 16 positive cases (\%), gray bar; HPV cocktail positive cases (\%), white bar; HPV negative cases (\%). (B) Distribution of HPV 16 in SCC and ACC.

was higher in HPV 16-positive cases than it was in HPV 16-negative cases in samples from Japan and Mongolia, respectively ( $p=0.0001 ; p=0.008$ Table 3 ). However, there was no significant correlation in samples from Myanmar.

\section{Correlation of HPV infection and p63 expression in normal} cervix, cervical intraepithelial neoplasia and cervical cancer

To clarify the relationship between HPV 16 infection and the squamous cell differentiation marker p63 expression 
Table 2. Clinicopathological or biological variables between HPV $16(+)$ and (-) and HPV cocktail (+) and all HPV (-) cervical cancer [Japan]

\begin{tabular}{|c|c|c|c|c|c|c|}
\hline \multirow{2}{*}{ Variables } & \multicolumn{3}{|c|}{ HPV 16} & \multicolumn{3}{|c|}{ HPV cocktail } \\
\hline & Positive $(n=29)$ & Negative $(n=11)$ & $p$ & Positive (HPV $16(-))(n=5)$ & Negative $(n=6)$ & $p$ \\
\hline \multicolumn{7}{|l|}{ Age group (years) } \\
\hline $25-40$ & 8 & 3 & & 2 & 1 & \\
\hline $41-56$ & 12 & 8 & NS & 3 & 4 & NS \\
\hline$\geq 57$ & 9 & 0 & & 0 & 1 & \\
\hline \multicolumn{7}{|l|}{ No of pregnancies } \\
\hline $1-2$ & 10 & 4 & & 2 & 1 & \\
\hline $3-5$ & 15 & 7 & NS & 3 & 5 & NS \\
\hline$\geq 6$ & 4 & 0 & & 0 & 0 & \\
\hline \multicolumn{7}{|l|}{ No of parities } \\
\hline 0 & 2 & 1 & & 1 & 0 & \\
\hline $1-2$ & 16 & 6 & NS & 2 & 2 & NS \\
\hline $3-5$ & 10 & 4 & & 2 & 4 & \\
\hline$\geq 6$ & 1 & 0 & & 0 & 0 & \\
\hline \multicolumn{7}{|l|}{ Histological type } \\
\hline $\mathrm{ACC}$ & 3 & 9 & $<0.0001$ & 4 & 5 & NS \\
\hline $\mathrm{SCC}$ & 26 & 2 & & 1 & 1 & \\
\hline Stage I/II & 20 & 11 & 0.0433 & 5 & 6 & NS \\
\hline III/IV & 9 & 0 & & 0 & 0 & \\
\hline
\end{tabular}

[Mongolia]

\begin{tabular}{|c|c|c|c|c|c|c|}
\hline \multirow{2}{*}{ Variables } & \multicolumn{3}{|c|}{ HPV 16} & \multicolumn{3}{|c|}{ HPV cocktail } \\
\hline & Positive $(n=21)$ & Negative $(n=11)$ & $p$ & Positive (HPV $16(-))(n=8)$ & Negative $(n=3)$ & $p$ \\
\hline \multicolumn{7}{|l|}{ Age group (years) } \\
\hline $25-40$ & 7 & 4 & NS & 3 & 1 & \\
\hline $41-56$ & 13 & 5 & & 4 & 1 & NS \\
\hline$\geq 57$ & 1 & 2 & & 1 & 1 & \\
\hline \multicolumn{7}{|l|}{ No of pregnancies } \\
\hline $1-2$ & 2 & 4 & & 2 & 2 & \\
\hline $3-5$ & 10 & 2 & NS & 2 & 0 & NS \\
\hline$\geq 6$ & 9 & 5 & & 4 & 1 & \\
\hline \multicolumn{7}{|l|}{ No of parities } \\
\hline 0 & 0 & 1 & & 0 & 1 & \\
\hline $1-2$ & 9 & 4 & NS & 3 & 1 & NS \\
\hline $3-5$ & 7 & 4 & & 3 & 1 & \\
\hline$\geq 6$ & 5 & 2 & & 2 & 0 & \\
\hline \multicolumn{7}{|l|}{ Histological type } \\
\hline ACC & 0 & 4 & 0.0092 & 1 & 3 & 0.0242 \\
\hline $\mathrm{SCC}$ & 21 & 7 & & 7 & 0 & \\
\hline Stage I/II & 16 & 7 & NS & 4 & 3 & NS \\
\hline III/IV & 5 & 4 & & 4 & 0 & \\
\hline
\end{tabular}

[Myanmar]

\begin{tabular}{|c|c|c|c|c|c|c|}
\hline \multirow{2}{*}{ Variables } & \multicolumn{3}{|c|}{ HPV 16} & \multicolumn{3}{|c|}{ HPV cocktail } \\
\hline & Positive $(\mathrm{n}=15)$ & Negative $(\mathrm{n}=15)$ & $p$ & Positive (HPV $16(-))(n=7)$ & Negative $(\mathrm{n}=8)$ & $p$ \\
\hline Age group (years) & & & & & & \\
\hline $25-40$ & 6 & 1 & & 1 & 0 & \\
\hline $41-56$ & 3 & 13 & 0.0012 & 4 & 8 & NS \\
\hline$\geq 57$ & 6 & 1 & & 2 & 0 & \\
\hline No of pregnancies & & & & & & \\
\hline $1-2$ & 2 & 2 & & 1 & 1 & \\
\hline $3-5$ & 7 & 6 & NS & 1 & 5 & NS \\
\hline$\geq 6$ & 6 & 7 & & 5 & 2 & \\
\hline No of parities & & & & & & \\
\hline 0 & 0 & 0 & & 0 & 0 & \\
\hline $1-2$ & 3 & 3 & NS & 2 & 1 & NS \\
\hline $3-5$ & 11 & 8 & & 2 & 6 & \\
\hline$\geq 6$ & 1 & 4 & & 3 & 1 & \\
\hline Histological type & & & & & & \\
\hline $\mathrm{ACC}$ & 0 & 6 & 0.0169 & 4 & 2 & NS \\
\hline $\mathrm{SCC}$ & 15 & 9 & & 3 & 6 & \\
\hline Stage I/II & 14 & 11 & NS & 6 & 5 & NS \\
\hline III/IV & 1 & 4 & & 1 & 3 & \\
\hline
\end{tabular}

SCC, squamous cell carcinoma; ACC, adenocarcinoma. 


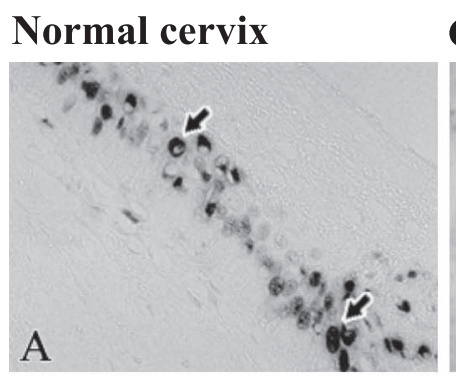

\section{CIN I}
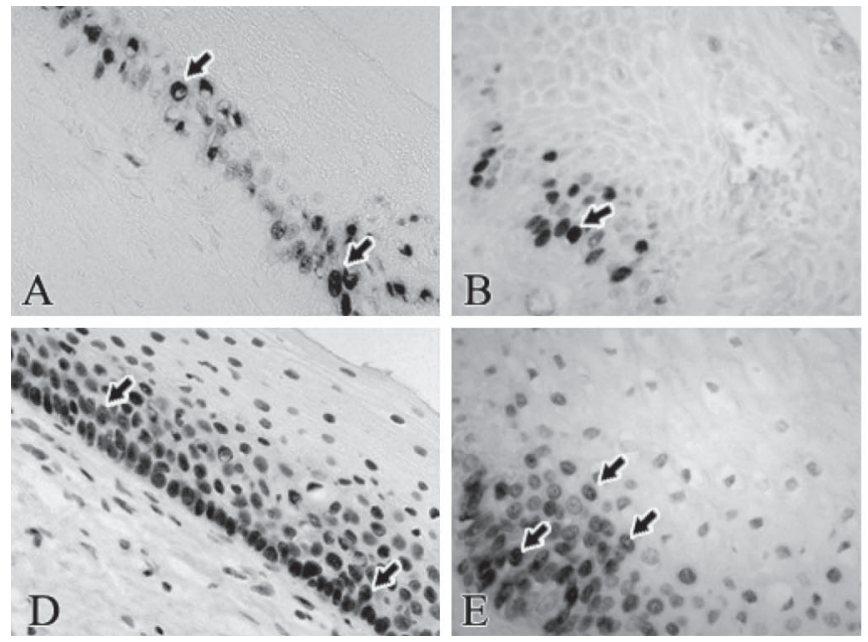

\section{CIN III}
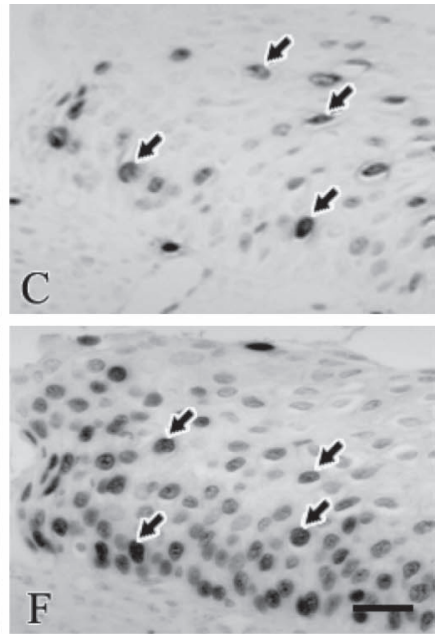

Fig. 3. Ki-67 and p63 localization in normal cervix, cervical intraepithelial neoplasia (CIN) I and III. (A-C) In normal cervix, Ki-67 was localized in parabasal cells. In CIN I to III, Ki-67 expression spread from parabasal layer to the superficial layer. (D-F) p63 staining in normal cervix, CIN I and CIN III. In normal cervix, p63 was localized in the nuclei of basal and parabasal cells. In CIN I to III, p63 was spread from basal layer to the surface epithelium. Arrows indicate positive cells for Ki-67 and p63 in normal cervix, CIN I and CIN III. Bar=20 $\mu \mathrm{m}$.

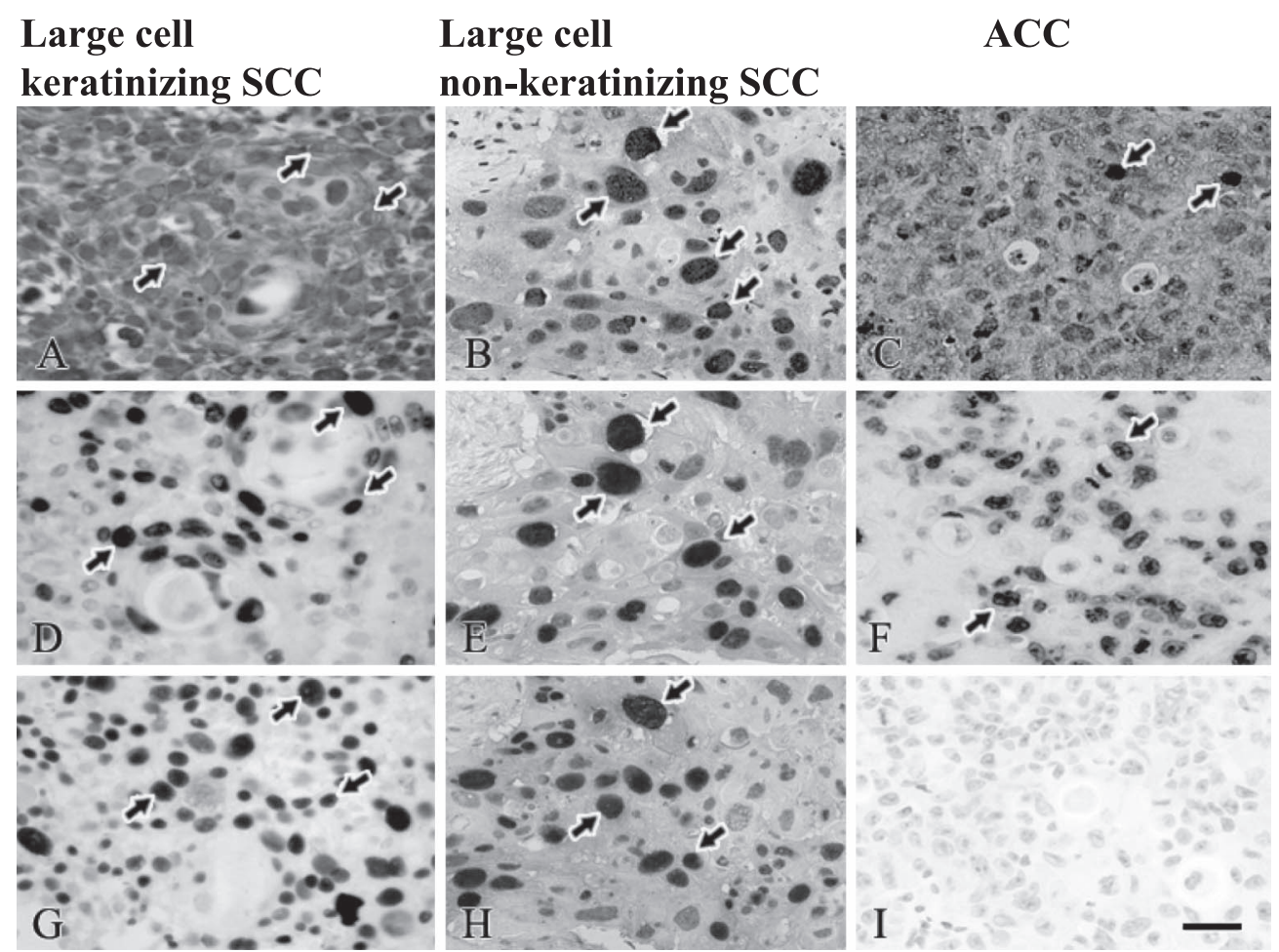

Fig. 4. A and C: Localization of HPV 16; B: HPV cocktail; D-F: Ki-67 and G-I: p63 in cervical cancer. (A, D and G) The panels were obtained from large cell keratinizing SCC, (B, E and $\mathbf{H})$ from large cell non-keratinizing SCC and $(\mathbf{C}, \mathbf{F}$ and $\mathbf{I})$ ACC of each adjacent sections. (D, G, E and $\mathbf{H}$ ) Ki-67 and p63-positive cells were abundant in SCC; however, (I) p63 was negative in ACC. (A and D, B and E) HPV 16 and HPV cocktail were co-expressed with Ki-67 in SCC. Arrows indicate positive cells for HPV 16, Ki-67 and p63 in cervical cancer. Bar=20 $\mu \mathrm{m}$.

was examined in normal cervix, CIN and cervical cancer tissues. As shown in Figure 3, p63 expression in normal stratified squamous epithelium was found in the nuclei of parabasal and basal cells, whereas p63 expression in
CIN I to III increased progressively from the basal layer to the surface, similar to the expression of Ki-67 (Fig. 3D-F, discussed below). p63 expression was consistently higher in SCC throughout the entire thickness of the tumor, 
Table 3. Correlation between HPV 16 and p63 labeling index in squamous cell carcinoma

\begin{tabular}{|c|c|c|c|c|c|c|c|c|c|}
\hline \multirow[b]{2}{*}{ Variables } & \multicolumn{3}{|c|}{ HPV 16 (Japan) } & \multicolumn{3}{|c|}{ HPV 16 (Mongolia) } & \multicolumn{3}{|c|}{ HPV 16 (Myanmar) } \\
\hline & $\begin{array}{l}\text { Positive } \\
(n=26)\end{array}$ & $\begin{array}{c}\text { Negative } \\
(\mathrm{n}=2)\end{array}$ & $p$ & $\begin{array}{c}\text { Positive } \\
(n=21)\end{array}$ & $\begin{array}{c}\text { Negative } \\
(n=7)\end{array}$ & $p$ & $\begin{array}{l}\text { Positive } \\
(n=15)\end{array}$ & $\begin{array}{c}\text { Negative } \\
(\mathrm{n}=9)\end{array}$ & $p$ \\
\hline $\begin{array}{l}\text { p63 LI } \\
(\%, \text { mean } \pm \text { SD })\end{array}$ & $53.6 \pm 10.7$ & $19.5 \pm 13.4$ & 0.0002 & $46.1 \pm 16.3$ & $30.8 \pm 14.4$ & 0.0398 & $28.4 \pm 14.7$ & $29.3 \pm 26.3$ & NS \\
\hline \multicolumn{10}{|c|}{ Distribution of $\mathrm{p} 63$} \\
\hline Negative & 0 & 1 & & 0 & 1 & & 0 & 2 & \\
\hline Low & 8 & 1 & 0.0007 & 5 & 4 & 0.0357 & 7 & 1 & NS \\
\hline High & 18 & 0 & & 16 & 2 & & 8 & 6 & \\
\hline $\begin{array}{l}\text { Ki-67 } \\
(\%, \text { mean } \pm \text { SD })\end{array}$ & $46.6 \pm 12.1$ & $28.5 \pm 11.9$ & 0.0001 & $37.0 \pm 22.1$ & $16.3 \pm 13.1$ & 0.008 & $12.4 \pm 12.0$ & $14.2 \pm 10.5$ & NS \\
\hline
\end{tabular}

Low, p63-positive cells $<32 \%$; High, p63-positive cells $>32 \%$; LI, labeling index.

HPV16

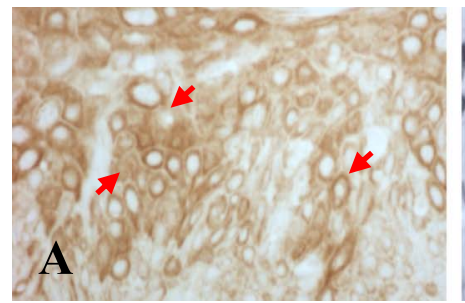

p63

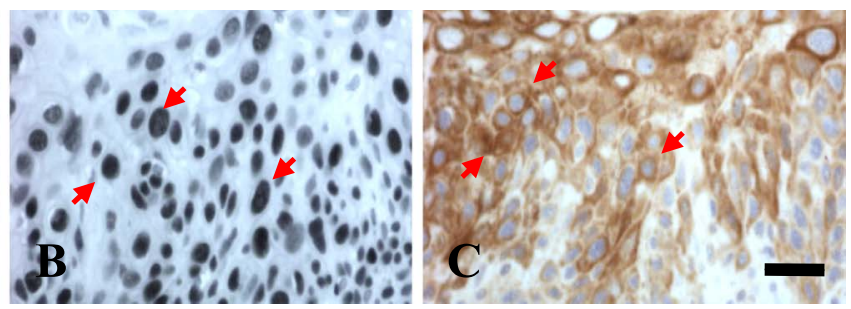

Fig. 5. Double immunostaining for HPV 16 and p63 in SCC. (A-C) Arrows indicate positive cells for HPV 16 and p63 in SCC. (C) HPV 16 immunoreactivity is detectable in most of the p63-positive nuclei. $\mathrm{Bar}=20 \mu \mathrm{m}$.

whereas p63 was not expressed in ACC (Fig. 4G-I). In SCC the ratio of p63-positive cells was higher in HPV-16positive cases compared with negative cases in samples from Japan and Mongolia ( $p=0.0002$ and $p=0.0398$, respectively; Table 3). However, a significant correlation was not seen in samples from Myanmar. The percentage of p63-positive cells varied from 5-70\% with a mean value \pm SD of $35.8 \pm 26.4$ in samples from Japan, 36.8 \pm 21.9 in samples from Mongolia, and $24.5 \pm 20.7$ in samples from Myanmar, for an average of $32.3 \pm 23 \%$. Therefore, we were categorized as low $(<32 \%)$ and high $(>32 \%$; Table 3$)$, depending upon the percentage of p63-positive cells in SCC. High p63-positive cells were observed in HPV 16-positive SCCs in samples from Japan and Mongolia ( $p=0.0007 ; p=0.0357$, respectively). Moreover, p63 and HPV 16 were co-expressed in cancer cells as identified by double staining (Fig. 5C).

\section{Correlation between p63 and Ki-67 expression in various stages of HPV 16-positive SCC}

To clarify the relationship between p63 expression and proliferating activity, double staining for p63 and Ki-67 was performed in normal cervix and HPV 16-positive SCC tissues in Figure 6A and B, respectively. When we examined the correlation between $\mathrm{Ki}-67$ and p63 LI in HPV 16positive SCC, both parameters were significantly correlated $(r=0.618, p=0.0005$; Fig. 6C). As for the correlation of the percentage of p63-positive cells and the stages of SCC, the percentage of p63-positive cells was significantly higher in stages III and IV than in stages I and II in samples from Japan and Mongolia ( $p=0.0011$ and $p=0.0385$, respectively, Table 4). Ki-67 LI was significantly higher in stages III and IV than in stages I and II in samples from Japan and Myanmar ( $p=0.0011$ and $p=0.0394$, respectively).

\section{Discussion}

In the present study, we assessed the type of HPV infection in cervical cancer in three geographically different countries, that is, Japan, Mongolia, and Myanmar, and found that HPV 16 was strongly associated with Japanese patients, whereas both HPV 16 and other HPV types were frequent in cervical cancer cases from Mongolia and Myanmar.

International studies of cervical cancer have shown that HPV 16 is the most prevalent type in Europe (65.1\%), North America (57.9\%), Central and South America (50.5\%) and Southeast Asia (42.9\%) [5]. In East and Southeast Asia, specifically, the most prevalent type among invasive cervical cancers is HPV16/18, followed by HPV 31/33 and $52 / 58[3,5]$. In Japan, the most common HPV types in cervical cancer are HPV 16/18 (58.8\%) and 31/33 (11.5\%) [22]. In our study, HPV 16 was the most prevalent type, and other HPV types (HPV 1, 6, 11, 18 and 31) were also prevalent, though less so, among Japanese, Mongolian and Myanmar cervical cancer samples. A pooled analysis of invasive cervical cancer in Southeast Asia demonstrated that 


\section{A. Normal cervix}

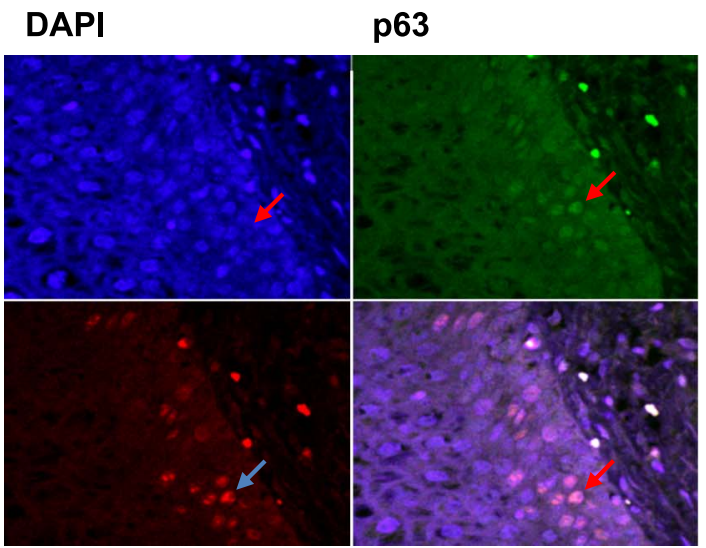

Ki-67

C

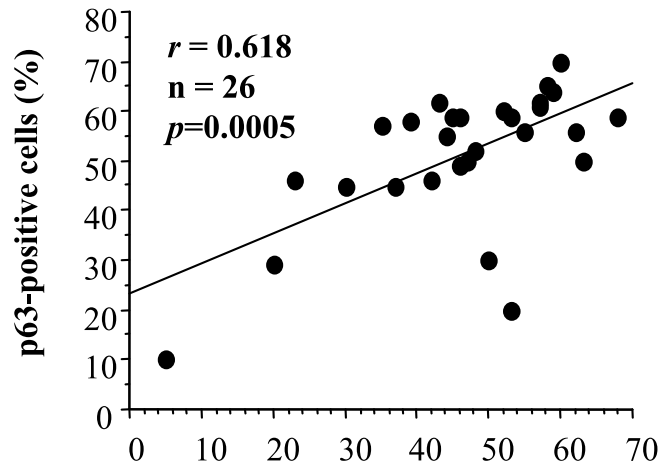

Ki-67 labeling index (\%)

\section{B. SCC}

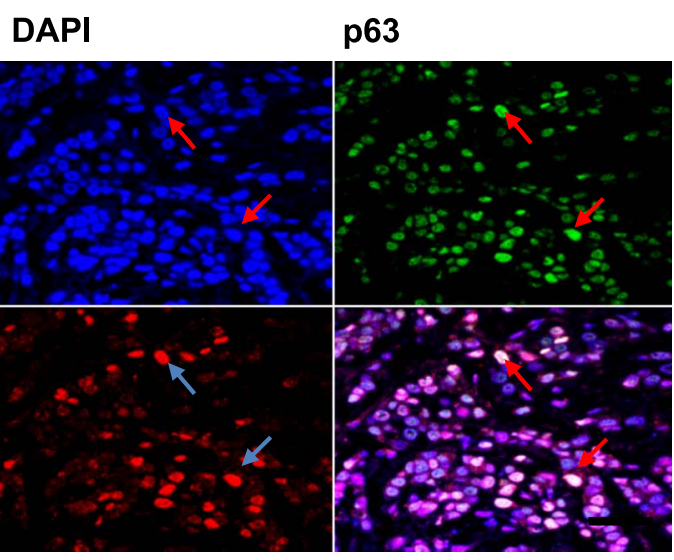

Ki-67

Merge

Fig. 6. Colocalization of p63 and Ki-67 in normal cervix and SCC by immunofluorescent staining. (A) p63 and Ki-67 were colocalized in some parabasal and basal epithelial cells of normal cervix and are visualized as white nuclei in the merged image. (B) p63 and Ki-67 were extensively colocalized (white nuclei) in merged image of SCC. Nuclei were counterstained with DAPI. Arrows indicate positive cells for p63, Ki-67 and DAPI in normal cervix and SCC. Bar $=20 \mu \mathrm{m}$. (C) Correlation between percentage of p63-positive cells and Ki-67 labeling index (LI) in HPV 16-positive $\operatorname{SCC}(r=0.618, p=0.0005)$.

Table 4. Association between p63 or Ki-67 labeling index (mean $\pm S D$ ) and stage of cervical cancer

\begin{tabular}{lllccc}
\hline \multicolumn{1}{c}{ Variables } & & $\mathrm{p} 63$ & $p$ & $\mathrm{Ki}-67$ LI & $p$ \\
\hline Japan & & & & & \\
Stage I, II & $(\mathrm{n}=31)$ & $28.4 \pm 26.4$ & $\mathbf{0 . 0 0 1 1}$ & $37.4 \pm 14.2$ & $\mathbf{0 . 0 0 1 1}$ \\
Stage III, IV & $(\mathrm{n}=9)$ & $61.8 \pm 4.3$ & & $55.7 \pm 5.4$ & \\
\hline Mongolia & & & & & \\
Stage I, II & $(\mathrm{n}=23)$ & $33.8 \pm 21.3$ & $\mathbf{0 . 0 3 8 5}$ & $29.6 \pm 24.8$ & $\mathrm{NS}$ \\
Stage III, IV & $(\mathrm{n}=9)$ & $50.4 \pm 13.3$ & & $38.6 \pm 13.3$ & \\
\hline Myanmar & & & & & \\
Stage I, II & $(\mathrm{n}=25)$ & $24.6 \pm 22.6$ & $\mathrm{NS}$ & $11.4 \pm 11.0$ & $\mathbf{0 . 0 3 9 4}$ \\
Stage III, IV & $(\mathrm{n}=5)$ & $24.4 \pm 7.3$ & & $22.6 \pm 6.5$ & \\
\hline
\end{tabular}

LI, labeling index.

HPV $16 / 18$ is associated with $73.5 \%$, HPV 45 with $7.9 \%$ and HPV 52/58 with $6.1 \%$ of the cases [22]. Particularly, in Thailand, HPV 52 and 58 were found in $17.7 \%$ of cervical cancers [33]. In this study, all HPV-negative cases were higher in Myanmar than in Japan and Mongolia, indicating that other high risk-HPV types such as HPV 45 and HPV
52/58 may be associated with cervical cancer in Myanmar, similar to other regions of Southeast Asia. In addition, in developing countries, such as Mongolia and Myanmar, there is a lack of nationwide screening programs as well as of general health knowledge about cervical cancer. In Myanmar, it may be suggested that women who live in rural areas suffer from higher incidence of cervical cancer because they lack sufficient supply of clean water for bathing. Therefore, the survey of HPV types has important implications for HPV vaccine strategies to prevent cervical cancer in these countries, and immunohistochemical technique may be enough to detect the HPV type for these developing countries.

Integration of high-risk HPV DNA into the host-cell genome results in elevated expression levels of E6 and E7, the early HPV proteins that contribute to tumor progression by inactivating cellular tumor suppressor proteins p53 and retinoblastoma, and thus altering cell cycle control $[6,30]$. Together, these alterations lead to acceleration of the cell cycle, with an increased proliferation rate, as indicated by high Ki-67 LI and acquisition of more genetic damage in HPVinfected cancer cells [2]. Previously, Nair et al. [24] demon- 
strated that HPV 16 and 18 infections resulted in increased tumor cell proliferation in SCC. Bahnassy et al. [2] reported that a high Ki-67 LI was significantly associated with stage and overall survival in patients with invasive SCC. We also found the association of $\mathrm{Ki}-67 \mathrm{LI}$ with the stage of cervical cancer.

p63 is the newest member of the p53 tumor suppressor gene family [41, 42]. Transcriptionally active (TA) p63 induces p53 target genes and can induce cell cycle arrest and apoptosis, whereas aminoterminally truncated $(\Delta N)$ p63 inactivates p53, thus having anti-apoptotic activity [41]. $\Delta \mathrm{Np} 63$ is highly expressed in stem cells of epithelial tissue and is required for proliferation and maintenance of the epithelial stem cell population [28, 32]. Previous studies have indicated that TAp63 promotes epithelial cell differentiation, whereas $\Delta \mathrm{Np} 63$ favors epithelial cell proliferation $[8$, 18]. In the present study we found the over-expression of p63 isoforms (TA and $\Delta N$ ) and the association of p63 with cell proliferation in SCC, which together may promote carcinogenesis in cervical cancer. Increased p63 staining has been reported in head, neck, lung, esophageal, and oral SCCs, and p63 might also function as a marker of metaplastic breast carcinoma $[8,15]$. Interestingly, increased expression of p63 was highly correlated with the stage of cervical cancer, suggesting the possible association with the tumor progression for SCC. Furthermore, we found the correlation between p63 and HPV 16 expression in SCC, suggesting that HPV 16 presents a trophism for squamous epithelial cells, while p63 may provide a positive contribution to the viral life cycle by blocking apoptosis through the $\Delta \mathrm{Np} 63$ isoforms [4].

In conclusion, it is suggested that HPV 16 may be associated with the cell proliferative activity, and also may be correlated with the expression of $\mathrm{p} 63$, which has a possible role for tumor progression in the cervical cancer. Our study indicates that HPV 16 infection is associated strongly with the Japanese population, whereas both HPV 16 and other types were similarly frequent in the populations of Mongolia and Myanmar. Therefore, it is emphasized that the rationale for HPV screening and the use of the HPV vaccine depending upon the HPV types to prevent cervical cancer in Japan, Mongolia, and Myanmar.

\section{Acknowledgments}

This study was supported in part by a Grant-in-Aid for Scientific Research from the Japanese Ministry of Education, Science, Sports and Culture (nos. 13576001, 16406005, 18390060, and 19406005), and a Grant for Advanced Start-up Program from Nagasaki University.

\section{References}

1. Baekelandt, M., Holm, R., Nesland, J. M., Trope, C. G. and Kristensen, G. B. (2000) Expression of apoptosis-related proteins is an independent determinant of patient prognosis in advanced ovarian cancer. J. Clin. Oncol. 18; 3775-3781.
2. Bahnassy, A. A., Zekri, A. R., Saleh, M., Lotayef, M., Moneir, M. and Shawki, O. (2007) The possible role of cell cycle regulators in multistep process of HPV-associated cervical carcinoma. BMC Clin. Pathol. 7; 4.

3. Bao, Y. P., Li, N., Smith, J. S. and Qiao, Y. L., ACCPAB members. (2008) Human papillomavirus type distribution in women from Asia: a meta-analysis. Int. J. Gynecol. Cancer 18; 71-79.

4. Blandino, G. and Dobbelstein, M. (2004) p73 and p63: why do we still need them? Cell Cycle 3; 886-894.

5. Bosch, F. X., Manos, M. M., Munoz, N., Sherman, M., Jansen, A. M., Peto, J., Schiffman, M. H., Moreno, V., Kurman, R. and Shah, K. V. (1995) Prevalence of human papillomavirus in cervical cancer: a worldwide perspective. International biological study on cervical cancer (IBSCC) study group. J. Natl. Cancer Inst. 87; 796-802.

6. Clarke, B. and Chetty, R. (2001) Cell cycle aberrations in the pathogenesis of squamous cell carcinoma of the uterine cervix. Gynecol. Oncol. 82; 238-246.

7. Creasman, W. T. (1990) New gynecologic cancer staging. Obstet. Gynecol. 75; 287-288.

8. Di Como, C. J., Urist, M. J., Babayan, I., Drobnjak, M., Hedvat, C. V., Teruya-Feldstein, J., Pohar, K., Hoos, A. and CordonCardo, C. (2002) p63 expression profiles in human normal and tumor tissues. Clin. Cancer Res. 8; 494-501.

9. Garland, S. M., Tabrizi, S. N., Chen, S., Byambaa, C. and Davaajav, K. (2001) Prevalence of sexually transmitted infections (Neisseria gonorrhoeae, Chlamydia trachomatis, Trichomonas vaginalis and human papillomavirus) in female attendees of a sexually transmitted diseases clinic in Ulaanbaatar, Mongolia. Infect. Dis. Obstet. Gynecol. 9; 143-146.

10. Genther, S. M., Sterling, S., Duensing, S., Münger, K., Sattler, C. and Lambert, P. F. (2003) Quantitative role of the human papillomavirus type $16 \mathrm{E} 5$ gene during the productive stage of the viral life cycle. J. Virol. 77; 2832-2842.

11. Hishikawa, Y., An, S., Yamamoto-Fukuda, T., Shibata, Y. and Koji, T. (2009) Improvement of in situ PCR by optimization of PCR cycle number and proteinase $\mathrm{K}$ concentration: localization of X chromosome-linked phosphoglycerate kinase-1 gene in mouse reproductive organs. Acta Histochem. Cytochem. 42; 1521.

12. Hu, H., Xia, S. H., Li, A. D., Xu, X., Cai, Y., Han, Y. L., Wei, F., Chen, B. S., Huang, X. P., Han, Y. S., Zhang, J. W., Zhang, X., Wu, M. and Wang, M. R. (2002) Elevated expression of p63 protein in human esophageal squamous cell carcinomas. Int. $J$. Cancer 102; 580-583.

13. Johnson, K. M., Kines, R. C., Roberts, J. N., Lowy, D. R., Schiller, J. T. and Day, P. M. (2009) Role of heparan sulfate in attachment to and infection of the murine female genital tract by human papillomavirus. J. Virol. 83; 2067-2074.

14. Kato, K., Hasui, K., Wang, J., Kawano, Y., Aikou, T. and Murata, F. (2008) Homeostatic mass control in gastric non-neoplastic epithelia under infection of Helicobacter pylori: An immunohistochemical analysis of cell growth, stem cells and programmed cell death. Acta Histochem. Cytochem. 41; 23-38.

15. Koker, M. M. and Kleer, C. G. (2004) p63 expression in breast cancer: a highly sensitive and specific marker of metaplastic carcinoma. Am. J. Surg. Pathol. 28; 1506-1512.

16. Kurita, T., Cunha, G. R., Robboy, S. J., Mills, A. A. and Medina, R. T. (2005) Differential expression of p63 isoforms in female reproductive organs. Mech. Dev. 122; 1043-1055.

17. Liao, Z., Boileau, T. W., Erdman, J. W. Jr. and Clinton, S. K. (2002) Interrelationships among angiogenesis, proliferation, and apoptosis in the tumor microenvironment during $\mathrm{N}$-methyl- $\mathrm{N}$ nitrosourea androgen-induced prostate carcinogenesis in rats. Carcinogenesis 23; 1701-1711.

18. Lin, Z., Nan, Y., Zhang, X., Zhao, Y., Kim, C. and Kim, I. (2006) 
Reverse transcription-polymerase chain reaction and western blotting analysis for detection of $\mathrm{p} 63$ isoforms in uterine cervical cancers. Int. J. Gynecol. Cancer 16; 1643-1647.

19. Massion, P. P., Taflan, P. M., Jamshedur Rahman, S. M., Yildiz, P., Shyr, Y., Edgerton, M. E., Westfall, M. D., Roberts, J. R., Pietenpol, J. A., Carbone, D. P. and Gonzalez, A. L. (2003) Significance of p63 amplification and overexpression in lung cancer development and prognosis. Cancer Res. 63; 7113-7121.

20. Matsuo, Y., Nomata, K., Eguchi, J., Aoki, D., Hayashi, T., Hishikawa, Y., Kanetake, H., Shibata, Y. and Koji, T. (2007) Immunohistochemical analysis of connexin43 expression in infertile human testes. Acta Histochem. Cytochem. 40; 69-75.

21. McLean, C. S., Churcher, M. J., Meinke, J., Smith, G. L., Higgins, G., Stanley, M. and Minson, A. C. (1990) Production and characterization of a monoclonal antibody to human papillomavirus type 16 using recombinant vaccine virus. J. Clin. Pathol. 43; 488-492.

22. Miura, S., Matsumoto, K., Oki, A., Satoh, T., Tsunoda, H., Yasugi, T., Taketani, Y. and Yoshikawa, H. (2006) Do we need a different strategy for HPV screening and vaccination in East Asia?. Int. J. Cancer 119; 2713-2715.

23. Münger, K. (2002) The role of human papillomaviruses in human cancers. Front. Biosci. 7; 641-649.

24. Nair, P., Nair, K. M., Jayaprakash, P. G. and Pillai, M. R. (1999) Decreased programmed cell death in the uterine cervix associated with high risk human papillomavirus infection. Pathol. Oncol. Res. 5; 95-103.

25. Nylander, K., Coates, P. J. and Hall, P. A. (2000) Characterization of the expression pattern of p $63 \alpha$ and $\Delta \mathrm{Np} 63 \alpha$ in benign and malignant oral epithelial lesions. Int. J. Cancer 87; 368-372.

26. Pisani, P., Parkin, D. M., Muñoz, N. and Ferlay, J. (1997) Cancer and infection: estimates of the attributable fraction in 1990 Cancer Epidemiol. Biomarkers Prev. 6; 387-400.

27. Quade, B. J., Yang, A., Wang, Y., Sun, D., Park, J., Sheets, E. E., Cviko, A., Federschneider, J. M., Peters, R., McKeon, F. D. and Crum, C. P. (2001) Expression of the p53 homologues p63 in early cervical neoplasia. Gynecol. Oncol. 80; 24-29.

28. Reis-Filho, J. S. and Schmitt, F. C. (2002) Taking advantage of basic research: p63 is a reliable myoepithelial and stem cell marker. Adv. Anat. Pathol. 9; 280-289.

29. Sasagawa, T., Basha, W., Yamazaki, H. and Inoue, M. (2001) High-risk and multiple human papillomavirus infections associated with cervical abnormalities in Japanese women. Cancer Epidemiol. Biomarkers Prev. 10; 45-52.

30. Scheffner, M., Münger, K., Byrne, J.C. and Howley, P. M. (1991) The state of the $\mathrm{p} 53$ and retinoblastoma genes in human cervical carcinoma cell lines. Proc. Natl. Acad. Sci. U S A 88; 5523-5527.

31. Shukuwa, K., Izumi, S., Hishikawa, Y., Ejima, K., Inoue, S., Muramatsu, M., Ouchi, Y., Kitaoka, T. and Koji, T. (2006) Diethylstilbestrol increases the density of prolactin cells in male mouse pituitary by inducing proliferation of prolactin cells and transdifferentiation of gonadotropic cells. Histochem. Cell Biol. $126 ; 111-123$.

32. Signoretti, S., Waltregny, D., Dilks, J., Isaac, B., Lin, D.,
Garraway, L., Yang, A., Montironi, R., McKeon, F. and Loda, M. (2000) p63 is a prostate basal cell marker and is required for prostate development. Am. J. Pathol. 157; 1769-1775.

33. Siriaunkgul, S., Suwiwat, S., Settakorn, J., Khunamornpong, S., Tungsinmunkong, K., Boonthum, A., Chaisuksunt, V., Lekawanvijit, S., Srisomboon, J. and Thorner, P. S. (2008) HPV genotyping in cervical cancer in Northern Thailand: adapting the linear array HPV assay for use on paraffin-embedded tissue. Gynecol. Oncol. 108; 555-560.

34. Stefansson, I. M., Salvesen, H. B. and Akslen, L. A. (2006) Loss of p63 and cytokeratin 5/6 expression is associated with more aggressive tumors in endometrial carcinoma patients. Int. J. Cancer 118; 1227-1233.

35. Suzuki, T., Matsuzaki, T., Hagiwara, H., Aoki, T. and Takata, K. (2007) Recent advances in fluorescent labeling techniques for fluorescence microscopy. Acta Histochem. Cytochem. 40; 131137.

36. Ulziibat, S., Ejima, K., Shibata, Y., Hishikawa, Y., Kitajima, M., Fujishita, A., Ishimaru, T. and Koji, T. (2006) Identification of estrogen receptor $\beta$-positive intraepithelial lymphocytes and their possible roles in normal and tubal pregnancy oviducts. Hum. Reprod. 21; 2281-2289.

37. Urist, M. J., Di Como, C. J., Lu, M. L., Charytonowicz, E., Verbel, D., Crum, C. P., Ince, T. A., McKeon, F. D. and CordonCardo, C. (2002) Loss of p63 expression is associated with tumor progression in bladder cancer. Am. J. Pathol. 161; 1199-1206.

38. Wang, T. Y., Chen, B. F., Yang, Y. C., Chen, H., Wang, Y., Cviko, A., Quade, B. J., Sun, D., Yang, A., McKeon, F. D. and Crum, C. P. (2001) Histologic and immunophenotypic classification of cervical carcinomas by expression of the p53 homologue p63: a study of 250 cases. Hum. Pathol. 32; 479-486.

39. WHO (2002) Disease specific NCD morbidity and mortality profile. In "Noncommunicable Diseases in the South-East Asia Region-A Profile”. New Delhi, pp. 46-48.

40. Woodman, C. B., Collins, S. I. and Young, L. S. (2007) The natural history of cervical HPV infection: Unresolved issues. Nat. Rev. Cancer 7; 11-22.

41. Yang, A., Kaghad, M., Wang, Y., Gillett, E., Fleming, M. D., Dötsch, V., Andrews, N. C., Caput, D. and McKeon, F. (1998) p63, a p53 homologue at 3q27-29, encodes multiple products with transactivating, death-inducing, and dominant-negative activities. Mol. Cell 2; 305-316.

42. Yang, A., Schweitzer, R., Sun, D., Kaghad, M., Walker, N., Bronson, R. T., Tabin, C., Sharpe, A., Caput, D., Crum, C. and McKeon, F. (1999) p63 is essential for regenerative proliferation in limb, craniofacial and epithelial development. Nature 398; 714-718.

43. zur Hausen, H. (2002) Papillomaviruses and cancer: from basic studies to clinical application. Nat. Rev. Cancer 2; 342-350.

This is an open access article distributed under the Creative Commons Attribution License, which permits unrestricted use, distribution, and reproduction in any medium, provided the original work is properly cited. 